Camargo, A., Loureiro, O. I. \& Sodré, G. (2018). Se gosta de cocriar, gosta de ser empoderado? Co-criação dos clients e suas preferências pelo empoderamento. Consumer Behavior

\title{
SE GOSTA DE CO-CRIAR, GOSTA DE SER EMPODERADO? CO-CRIAÇÃO DOS CLIENTES E SUAS PREFERÊNCIAS PELO EMPODERAMENTO
}

\author{
Altair Camargo \\ Orlando Isidoro Loureiro \\ Giovanna Sodré
}

\begin{abstract}
Altair Camargo é Doutorando do Programa de Pós-Graduação em Administração da Universidade de São Paulo - FEA/USP. E-mail: altaircamargo@usp.br.

Orlando Isidoro Loureiro é Doutorando do Programa de Pós-Graduação em Administração da Universidade de São Paulo - FEA/USP. E-mail:

o.loureiro@usp.br.

Giovanna Sodré é Graduada em Administração pela Faculdade de Administração, Ciências Contábeis e Ciências Econômicas da Universidade Federal de Goiás, FACE/UFG. E-mail: giovannasodre@gmail.com.

Os autores agracedecem aos avaliadores pelos comentários para melhoria do artigo.
\end{abstract}

\begin{abstract}
Resumo
0 objetivo desse artigo é verificar se há diferença na preferência dos clientes (tenham eles maior ou menor tendência a ter comportamento de co-criação) em relação aos tipos de empresas (considerando as que empoderam ou não os clientes). Para atingir o objetivo foi aplicado um questionário em que se mediu o comportamento de co-criação de valor dos indivíduos e suas preferências por empresas que oferecem o empoderamento a seus clientes. Escolheu-se como contexto as academias de ginástica, uma vez que se trata de um setor de serviços com ampla co-criação e empoderamento do consumidor. A análise dos dados coletados foi feita por meio de análise fatorial, regressão logística multinomial e teste $t$. Como resultado, verificou-se não haver relação entre grupos de consumidores e propensão a co-criação e preferência pelos tipos de empresas.

Palavras-chave: Co-criação, Empoderamento do consumidor, Setor de serviços.
\end{abstract}

Esta obra está licenciada com uma Licença Creative Commons Atribuição 4.0 Internacional.

\section{INTRODUÇÃO}

A co-criação de valor refere-se ao processo de interação entre empresa e consumidores com o objetivo de criar objetos ou serviços que tenham valor para as duas partes (Grönroos, 2000). Nas operações mercadológicas, a lógica do serviço dominante (perspectiva apresentada por Vargo e Lusch (2004) em que o serviço é entendido como algo que vai além do suporte ao produto), a criação de valor não depende somente das empresas, mas também dos clientes. Ou seja, os clientes são tratados como 
elementos que criam este valor juntamente com as organizações, como participantes ativos e parceiros envolvidos na cadeia de criação de valor em serviços (Yi \& Gong, 2013).

Tradicionalmente, as empresas se esforçam para aumentar a satisfação dos consumidores ao modificar recursos da própria organização, tais como materiais, promoção ou engajamento dos funcionários. Apesar de essa abordagem ter sua relevância, a literatura tem apresentado que consumidores que criam produtos e serviços em conjunto com as empresas apresentam maiores taxas de satisfação (Prentice, Han, \& Li, 2016). Assim como o melhor desempenho dos empregados de uma empresa faz com que o valor percebido de seus produtos e serviços pelos consumidores seja aumentado, o comportamento de co-criação de valor pelos indivíduos também incrementam este valor (Yi \& Gong, 2013). Em estudos relacionados à cocriação de valor em varejo, Shamim e Ghazali (2014) verificaram que consumidores envolvidos no processo de co-criação tendem a ficar mais tempo dentro das lojas, interagir mais com o ambiente e tornar as visitas ao local mais memoráveis, considerando-as como experiências mais difíceis de serem esquecidas.

Em relação ao exposto, há autores que apresentem escalas para se medir o comportamento do consumidor em relação à co-criação de valor (Yi \& Gong, 2013) e outros que criaram medidas para avaliar 0 empoderamento sentido pelos consumidores em relação às empresas (Prentice et al., 2016). Apesar disso, a literatura n通o deixa claro se é possível distinguir um grupo de clientes com tendência a ter maior comportamento de cocriação, bem como a relação entre o comportamento de co-criação e a preferência por empresas que permitam a co-criação. Ainda, Kukk, Leppiman e Pohjola (2015) mostraram que o engajamento do cliente em relação à cocriação de valor pode influenciar positivamente ou negativamente a percepção de valor dos serviços oferecidos pela empresa.

Com o objetivo de ter seu valor percebido e até aumentado, as empresas que permitem a cocriação de seus produtos e serviços com os consumidores devem fazer a divulgação da permissão deste processo. Para isso é necessário identificar quais são os consumidores que veem a interação e a cocriação como um processo favorável e adequar sua comunicação a este grupo de indivíduos para promover e incentivar ainda mais o processo (Grönroos, 2000). Assim, o objetivo deste artigo é verificar se há diferença na preferência dos clientes (tenham eles maior ou menor tendência a ter comportamento de cocriação) em relação aos tipos de empresa (considerando as que os empoderam ou não).

Este artigo contribui gerencialmente ao identificar que existem grupos de consumidores que tendem a ter um comportamento de cocriação e também suas preferências pelo empoderamento ou não. Assim, as empresas poderiam focar seus esforços em oferecer o empoderamento para os grupos de clientes que têm este desejo, enquanto os demais poderiam receber o valor da forma tradicional, ou seja, apenas oferecido pela empresa. Academicamente, o artigo traz um avanço na literatura ao fazer a relação entre o comportamento do indivíduo e suas preferências de consumo.

\section{REFERENCIAL TEÓRICO}

\section{Co-criação}

As primeiras discussões sobre co-criação aconteceram em meados da década de 1980, com a utilização do termo "prosumer", neologismo criado por Alvin Toffler na década de 1980, referindo-se aos indivíduos que participam da criação dos produtos ou serviços que irão consumir. Apesar disso, somente na inversão da lógica da dominância do produto para dominância do serviço, a partir do século 21 este assunto passou a ter mais atenção tanto da academia quanto das empresas (Terblanche, 2014). Esta atenção se concentra especialmente na discussão relacionada a marketing de serviços, que busca desenvolve-la em termos de rigor e de relevância. Esta discussão acadêmica envolve: o papel das empresas e clientes no sistema de co-criação de valor; de que forma ocorrem as experiências de co-criação de valor; os sistemas que favorecem o processo; e a cocriação de valor de uma perspectiva social (Shamim \& Ghazali, 2014).

0 termo co-criação é utilizado para se referir ao consumidor e sua interação com o desenvolvimento do produto, utilizando seu conheimento como um elemento de entrada do processo produtivo (Terblanche, 2014). Este processo gera valor tanto para o consumidor, 
que deixa de ser um sujeito passivo no relacionamento com a empresa, quanto para as organizações, ao adequarem suas ofertas às necessidades e desejos dos clientes (Grönroos, 2000).

Os estudos de Dijk, Antonides e Schillewaert (2014) reforçam que há indícios que a cocriação altera a forma como as marcas são utilizadas pelos clientes, bem como o valor percebido. Para compreender como a percepção de valor é formada, Kukk et al. (2015) realizaram entrevistas com gerentes de médio e alto escalão de prestadores de serviço e encontraram que, em geral, os clientes têm vontade de participar da criação dos serviços oferecidos pelas empresas. Além disso, os autores notaram que ao se envolverem no processo de co-criação, os clientes têm melhor percepção dos esforços das empresas para produzir os serviços e passam a ter expectativas mais reais em relação aos resultados finais.

Ainda em relação aos benefícios da cocriação, Dijk et al. (2014) mostraram que seu processo é percebido pelos clientes independentemente de uma marca ser ou não conhecida. Isso pode ser uma fonte de vantagem competitiva para aquelas empresas que não dispõem de tantos recursos para promoções de suas marcas, como os pequenos ou novos negócios. De forma geral, produtos apresentados como "co-criados juntamente com o consumidor" (pois poderiam ser co-criados com fornecedores ou mesmo colaboradores da empresa) são avaliados de forma mais positiva pelos clientes (Dijk et al., 2014; Fuchs \& Schreier, 2011), que os consideram mais atrativos, inovadores, únicos e mais alinhados com suas necessidades e desejos do que aqueles produtos que são apresentados como não tendo a participação do cliente em seu desenvolvimento. Desta forma, Dijk et al. (2014) ressaltam que seria interessante que as empresas que permitem a co-criação de produtos por seus consumidores façam ampla divulgação dessa prática.

A co-criação pressupõe que clientes (aqueles que compram produtos ou serviços das empresas) e consumidores (aqueles que usam os produtos ou serviços) aceitam, de forma espontânea, a interação com as organizações e são engajados a participar do processo (Vernette \& Hamdi-Kidar, 2013). Tal interação é visto tanto pela academia quanto pelas empresas como um desafio, uma vez que o próprio termo "co-criação" é novo. Por isso, é essencial que a empresa o explicite como algo além da pesquisa de mercado ou sugestões de clientes (Dijk et al., 2014). Assim, é recomendável que a empresa apresente os benefícios para os consumidores que aceitem participar da criação de produtos, sendo que tais benefícios podem ser hedônicos, cognitivos, de integração social ou pessoal (Vernette \& Hamdi-Kidar, 2013).

Vernette e Hamdi-Kidar (2013) apresentam dois tipos de clientes fundamentais para o processo de co-criação. 0 primeiro tipo se refere a clientes que são usuários maduros do produto que podem contribuir fornecendo ideias para necessidades específicas de uso daquele produto ou serviço, mais avançado do que o trivial já oferecido para a maioria dos demais usuários. 0 segundo tipo compreende clientes recém adquiridos, que podem contribuir imaginando como seria o produto diante do mercado atual e com as tendências que ele espera que o produto possa oferecer. Desta forma, as empresas deveriam focar seus esforços em identificar os usuários desses dois grupos e utiliza-los para a co-criação (Vernette \& Hamdi-Kidar, 2013).

Minkiewicz, Evans e Bridson (2014) desenvolveram uma estrutura em que a cocriação apresenta três facetas: a co-produção (que envolve a participação ativa e interação física), o engajamento (que envolve a imersão emocional e cognitiva) e a personalização (que envolve a customização da experiência, a interação com os empregados e a tecnologia oferecida). $\mathrm{Na}$ mesma estrutura, são apresentados os antecedentes do consumidor que levam à co-criação, representado pela exposição prévia à experiência, preconcepções individuais e interação com outros indivíduos.

A estrutura proposta por Hilton, Hughes e Chalcraft (2012) mostra que a contribuição de recursos por cada ator faz parte do processo de criação. A integração entre o que cada ator oferece causa a modificação desses recursos, que seria o valor produzido pelo processo e o sistema seria realimentado com esses novos recursos. Além disso, Hilton et al. (2012) pontuam que a co-criação e a co-produção são campos distintos e, no entendimento dos autores, a co-produção está relacionada à lógica de bens-dominante, em que o cliente apresenta 
apenas melhorias para o produto em si, enquanto a co-criação seria uma etapa além, baseada na lógica do serviço dominante. Assim, a co-criaçnao indica a integração de recursos como habilidades do consumidor e funcionários, conhecimentos e comportamentos necessários para criar serviços com a intenção de realizar uma proposição de valor.

Yi e Gong (2013) elaboraram a escala de comportamento de co-criação de valor utilizada neste estudo. Os autores consideram que este comportamento é um conceito multidimensional que envolve dois fatores de ordem elevada: comportamento de participação do consumidor e comportamento de cidadania do consumidor. No entendimento dos autores, cada um desses fatores são compostos por várias dimensões, sendo que o comportamento de participação é formado pela busca de informações, compartilhamento de informações, comportamento responsável e interação pessoal, e o comportamento de cidadania é formado pela predisposição a oferecer feedback, apoio, ajuda e a tolerância do indivíduo. Sendo assim, o modelo de Yi e Gong (2013) sugere um modelo hierárquico de três níveis.

A co-criação leva ao desenvolvimento de produtos mais eficientes por meio da redução de custos da criação, aumento da relevância do produto para o consumidor e ainda possibilita a adaptação mais assertiva em novos mercados (Dijk et al., 2014). Entretanto, as organizações devem estar atentas, pois, mesmo consumidores engajados podem não ter as competências necessárias para participarem de forma efetiva do processo de co-criação de produtos ou serviços (Vernette \& Hamdi-Kidar, 2013). O processo de co-criação é complexo, uma vez que envolve a integração de recursos e o entendimento de como tais recursos podem ser empregados e interligados uns com os outros da melhor forma possível (Hilton et al., 2012).

\section{Empoderamento dos Clientes pelas Empresas}

0 empoderamento é definido como um estado mental acompanhado por ações que permitem que os consumidores façam suas próprias escolhas nos mercados, baseando-se em suas necessidades, desejos e demandas (Tiu Wright, Pires, Stanton, \& Rita, 2006). Por exemplo, diz-se que uma empresa empodera o cliente quando permite que ele auxilia a criação e desenvolvimento de produtos e serviços da empresa, bem como altera processos. Assim, o empoderamento está relacionado com a cocriação na medida em que os consumidores recebem informações relevantes da empresa para poderem criar, em conjunto com ela, os produtos que desejam (Prentice et al., 2016).

As empresas têm empoderado seus consumidores, especialmente na indústria de serviços. Isso faz que os consumidores tenham mais informações antes de decidirem suas compras e, ainda, participarem do processo de criação do que será comprado (Prentice et al., 2016). Pesquisas têm demonstrado que o empoderamento do consumidor no desenvolvimento de produtos têm permitido que as empresas criem produtos melhores e reduzam custos e riscos de colocarem no mercado algo que não esteja de acordo com o que os consumidores pretendem adquirir ou utilizar (Fuchs \& Schreier, 2011). A Internet, por exemplo, é uma ferramenta que tem impulsionado o empoderamento (Prentice et al., 2016), uma vez que permite de forma relativamente simples o aumento da interação entre cliente e empresa. Além disso, por meio da rede os clientes consumidores podem facilmente comparar marcas, preços e conhecer informações de outros usuários em relação aos produtos.

Pesquisas de Fuchs e Schreier (2011) demonstraram que os consumidores estão mais propensos a utilizar produtos daquelas empresas que oferecem o empoderamento em relação àquelas empresas que não oferecem. Assim, o empoderamento do consumidor pode ser visto como um posicionamento estratégico a ser considerado pelos gestores para criar vantagem competitiva no mercado. A empresa pode, inclusive, trazer novamente os clientes que porventura possam ter tido uma experiência ruim com a organização no passado, uma vez que o empoderamento tem sido tratado como uma forma de atender benefícios dos clientes que não eram até então satisfeitos (Pranic \& Roehl, 2012). Essa ação pode ser analisada sob uma visão personalizada dos serviços de uma empresa visto que a mesma permite uma solução única para o cliente, acentuando a ligação entre ele a organização. Tais iniciativas podem acontecer, por exemplo, 
por meio da co-criação de produtos e serviços ou contribuição coletiva (Acar \& Puntoni, 2016).

0 empoderamento é um conceito que vai além da interação e engajamento do consumidor com as marcas (Acar \& Puntoni, 2016). Enquanto no engajamento os consumidores interagem com a marca por meio da divulgação das informações apresentadas por ela ou mesmo dialogam com as empresas (por exemplo, por meio das redes sociais), no empoderamento os clientes participam efetivamente da criação ou da escolha dos produtos e serviços que serão oferecidos pela organização, ou seja, oferecem o poder de decisão aos consumidores. Tradicionalmente, o empoderamento do consumidor é visto como uma forma de as empresas passarem tarefas para seus clientes e dividir essas tarefas e o gerenciamento das atividades entre os clientes e funcionários, algo que pode diminuir as taxas de reclamações, uma vez que os próprios clientes estarão envolvidos no processo de entrega do serviço (Pranic \& Roehl, 2012).

Há indícios de que mesmo aqueles clientes que não participam do empoderamento pelas empresas, ou seja, que são marginais a este processo, percebem que as empresas com esta atitude têm maior orientação ao consumidor. Desta forma, percebem a organização de forma positiva e tendem a escolher seus produtos em detrimento daquelas que não empoderam o consumidor e, ainda, fazer o boca-a-boca positivo dessas empresas (Fuchs \& Schreier, 2011).

Fuchs e Schreier (2011) afirmam ainda que o empoderamento dos consumidores pelas empresas pode se dar de duas formas principais: (1) aquelas empresas que permitem que o consumidor crie e apresente novas ideias para produtos; e (2) aquelas empresas que permitem que os consumidores escolham quais produtos serão produzidos. Nesse contexto, os autores apresentam uma matriz $2 \times 2$ em que no eixo horizontal está quem seleciona o que será produzido e no eixo vertical está quem desenvolve os novos produtos. Tanto em cada linha quanto em cada coluna da matriz há os termos "empresa" e "usuário". Assim, um produto pode ser criado e desenvolvido somente pela empresa (quando a linha e a coluna "empresa" se encontram) ou criado e decidido totalmente pelo usuário (quando a linha e a coluna "consumidor" se encontram).
Esta última situação seria aquela em que há o maior empoderamento do consumidor.

Prentice et al. (2016) desenvolveram uma escala para medir o empoderamento do consumidor com base em três dimensões: (1) escolha do serviço; (2) impacto; e (3) obtenção de informações. Tal escala foi desenvolvida por meio da geração de itens (com entrevistas em profundidade), refinamento (utilizando grupos focais) e validação (feita por meio de questionário). Os três fatores indicam que os consumidores percebem o empoderamento por meio do maior oferecimento de produtos pela empresa (escolha do serviço), capacidade de exercer influência no processo de entrega do produto (impacto) e o provimento de um canal de comunicação de duas vias por parte das empresas, de modo que os consumidores compartilhem suas experiências de consumo (obtenção de informações).

Para que um consumidor tenha um engajamento profundo com a empresa a partir do empoderamento que a organização dá a ele, é necessário que este consumidor dispense recursos como tempo ou dinheiro à organização (Acar \& Puntoni, 2016). Além disso, a empresa deve conhecer os recursos que o consumidor necessita para ter esse engajamento, podendo ser algo mais explícito como o dinheiro ou algo mais subjetivo como conhecimento prévio e/ou motivação (Hilton et al., 2012). Sendo assim, nem todos os consumidores estão dispostos a participarem de forma tão ativa no processo. Por isso, Acar e Puntoni (2016) sustentam que as empresas devem promover estratégias de empoderamento profundo e brandos ao mesmo tempo, uma vez que existem os clientes que têm vontade de participar dos processos de decisão das empresas mas não querem dispor muitos de seus recursos para isso. Ainda assim, estas empresas conseguiriam os benefícios do empoderamento - tanto para os clientes que participam dos processos de forma profunda e branda, quanto também para aqueles que observam o processo sem participar ativamente.

A partir da revisão de literatura, são propostas quatro hipóteses para este estudo:

$\mathrm{H}_{1}$ : Há diferença na pré-disposição à co-criação entre os indivíduos

$\mathrm{H}_{2}$ : Há diferença na preferência por empresas que praticam o empoderamento entre 
indivíduos

$\mathrm{H}_{3}$ : Indivíduos com alta pré-disposição à cocriação preferem empresas que praticam o empoderamento

$\mathrm{H}_{4}$ : As diferenças demográficas permitem a separação em grupos de acordo com a prédisposição dos indivíduos a praticarem a cocriação e preferirem empresas que oferecem ou não o empoderamento.

\section{MÉTODO}

Esta é uma pesquisa quantitativa de caráter descritivo que, para atingir o objetivo, foi dividida em duas partes. A primeira parte consistiu em verificar se há diferença no perfil da empresa que é considerada a preferida por indivíduos com diferentes níveis de comportamento de co-criação de valor. 0 método utilizado para essa parte da pesquisa foi a Análise Fatorial - AF, cuja finalidade é reduzir o número de fatores a serem analisados, o que possibilitou a identificação dos indivíduos com alto e baixo comportamento de co-criação de valor. Por meio de uma análise multivariada da variância (ANOVA), foi analisado se há diferença na preferência por empresas que permitem a co-criação entre os indivíduos com alto e baixo comportamento de co-criação de valor.

A segunda parte da pesquisa consistiu na identificação de grupos de indivíduos com alto e baixo comportamento de co-criação de valor e preferência por empresas que permitem ou não o empoderamento, utilizando as variáveis demográficas: renda, idade, e gênero para fazer a divisão entre os grupos. Esta identificação por grupos foi feita por meio de uma análise de regressão logística multinomial.

Como instrumento de coleta, foi utilizado um questionário online em que havia uma pergunta filtro questionando se o respondente frequentava regularmente academias de ginástica. Caso respondesse que sim, ele era orientado a responder o restante do questionário imaginando suas visitas a esta academia. Para este trabalho foi escolhida a academia de ginástica por se tratar de uma empresa tipicamente de serviços em que os usuários interagem diretamente com os funcionários e outros alunos. Foram obtidas 49 respostas, das quais 11 foram descartadas pois o respondentes nunca estiveram matriculados em uma academia (pergunta filtro). Desta forma, os dados foram analisados a partir de 38 respostas válidas.

Para a mensuração das variáveis que compõem o construto comportamento de cocriação dos indivíduos foi utilizada a escala proposta por Yi e Gong (2013), originalmente em inglês e convertida para português por meio da tradução reversa e adaptada para esta pesquisa. As questões utilizadas para o questionário estão apresentadas no Quadro 1 e o respondente tinha a opção de responde-las utilizando uma escala de 5 pontos, em que 1 indicava a opção "discordo totalmente" e 5 indicava a opção "concordo totalmente".

\begin{tabular}{|l|}
\hline Busca de informação \\
\hline Eu pedi informações para outras pessoas sobre o que a academia oferece \\
\hline Eu procurei por informações sobre onde a academia está localizada \\
\hline Eu prestei atenção no comportamento de outros frequentadores para usar bem a academia \\
\hline Compartilhamento de informação \\
\hline Eu explico (expliquei) claramente o que eu queria ao funcionário/instrutor \\
\hline Eu dou (dei) ao funcionário/instrutoras informações corretas que me foram solicitadas \\
\hline $\begin{array}{l}\text { Eu forneço (forneci) informações necessárias para que o funcionário/instrutorpudesse exercer } \\
\text { suas funções }\end{array}$ \\
\hline $\begin{array}{l}\text { Eu respondo (respondi) todas as questões relacionadas ao serviço oferecido pela academia feitas } \\
\text { pelo funcionário/instrutor }\end{array}$ \\
\hline Comportamento responsável \\
\hline Eu realizo (realizei) todas as tarefas que foram requeridas \\
\hline Eu completo (completei) adequadamente todos os comportamentos esperados \\
\hline Eu cumpro (cumpri) as obrigações requeridas pela academia \\
\hline Eu sigo (segui) as recomendações e ordens do instrutor \\
\hline Interação pessoal \\
\hline Eu sou (fui) amigável com o funcionário/instrutor \\
\hline Eu sou (fui) gentil com o funcionário/instrutor \\
\hline
\end{tabular}




\begin{tabular}{|l|}
\hline Eu sou (fui) educado com o funcionário/instrutor \\
\hline Eu sou (fui) cortês com o funcionário/instrutor \\
\hline Eu não ajo (agi) rudemente com o funcionário/instrutor \\
\hline Feedback \\
\hline Se eu tenho uma ideia útil para melhorar o serviço, eu conto para o funcionário/instrutor \\
\hline Quando eu recebo um bom serviço do funcionário/instrutor, eu comento sobre isso \\
\hline Quando eu tenho um problema, eu o digo para o funcionário/instrutor \\
\hline Apoio \\
\hline Eu falo coisas positivas sobre a academia e sobre o funcionário/instrutorpara outras pessoas \\
\hline Eu recomendo a academia e o funcionário/instrutorpara outras pessoas \\
\hline Eu estimulo amigos e parentes a usar a academia \\
\hline Ajuda \\
\hline Eu auxilio outros clientes se eles precisam da minha ajuda \\
\hline Eu ajudo outros clientes se eles parecem ter problemas \\
\hline Eu ensino outros clientes a usar os serviços da academia corretamente \\
\hline Eu dou conselhos a outros clientes \\
\hline Tolerância \\
\hline Mesmo que os serviços não sejam entregues como esperado, eu estaria disposto a aturá-lo \\
\hline Se o instrutor errar durante o serviço, eu estaria disposto a ser paciente \\
\hline $\begin{array}{l}\text { Se eu tiver que esperar mais do que eu normalmente espero para receber os serviços, eu estaria } \\
\text { disposto a me adaptar à nova situação }\end{array}$ \\
\hline Fonte: Adaptado de Yi e Gong (2013).
\end{tabular}

Quadro 1. Escala de comportamento de co-criação de valor

No questionário, além das questões relativas ao comportamento do indivíduo na co-criação de valor foram inseridas também perguntas relativas à sua preferência por visitar empresas que permitem e incentivam a co-criação de serviços. Estas perguntas foram adaptadas da escala de empoderamento psicológico do consumidor (customer pshycological empowerment), proposta por Prentice et al. (2016) e estão apresentadas no Quadro 2.

\begin{tabular}{|l|}
\hline Escolha do serviço \\
\hline Eu prefiro academias que me permitam escolher o lugar em que quero me exercitar \\
\hline Eu prefiro academias que me permitam escolher os professores que me atenderão \\
\hline Eu prefiro academias que me permitam utilizar seus serviços de diversas formas \\
\hline Impacto \\
\hline Eu prefiro academias que o serviço do empregado se ajuste conforme minha demanda \\
\hline Eu prefiro academias que o funcionário/instrutortrabalhe de acordo com minhas solicitações \\
\hline $\begin{array}{l}\text { Eu prefiro academias que o funcionário/instrutorrecomenda exercícios baseado na minha situação } \\
\text { pessoal }\end{array}$ \\
\hline $\begin{array}{l}\text { Eu prefiro academias que o funcionário/instrutordá as informações apropriadas baseado na minha } \\
\text { requisição }\end{array}$ \\
\hline Obtenção de informações \\
\hline Eu prefiro academias que eu seja capaz de obter informações dos bastidores \\
\hline Eu prefiro academias que eu seja capaz de obter informações sobre sua marca \\
\hline Eu prefiro academias que me permitam obter informações sobre o portfolio de serviços \\
\hline Fonte: Adaptado de Prentice et al. (2016).
\end{tabular}

Quadro 2. Escala de empoderamento psicológico do consumidor

Finalmente, o último bloco de perguntas do questionário se referia aos dados demográficos do respondente (idade, renda, gênero, há quanto tempo está matriculado regularmente em uma academia). Esses dados foram necessários para se fazer a análise de conglomerados da amostra. Os dados foram tratados e analisados por meio da versão 23 do software estatístico SPSS. 0 quadro 3 apresenta a matriz de amarração metodológica, ou seja, 
relaciona o modelo teórico, os objetivos de pesquisa, as hipóteses e as técnicas de análise em uma forma matricial conforme sugerido por
Mazzon em 1981 e analisado por Telles (2001) em relação à efetividade em pesquisas em Administração.

\begin{tabular}{|c|c|c|c|c|}
\hline \multicolumn{5}{|c|}{ Modelo teórico } \\
\hline \multicolumn{5}{|l|}{ Busca de informações } \\
\hline \multicolumn{5}{|l|}{$\begin{array}{l}\text { Compartilhamento } \\
\text { de informações }\end{array}$} \\
\hline \multicolumn{5}{|l|}{$\begin{array}{l}\text { Comportamento } \\
\text { responsável }\end{array}$} \\
\hline Interação social & $\begin{array}{l}\text { Pré-disposição à } \\
\text { co-criação }\end{array}$ & \multicolumn{2}{|c|}{$\begin{array}{l}\text { Preferência por } \\
\text { empoderamento }\end{array}$} & Impacto \\
\hline \multicolumn{5}{|l|}{ Feedback } \\
\hline \multicolumn{5}{|r|}{$\begin{array}{c}\text { Obtenção } \\
\text { de informações }\end{array}$} \\
\hline \multicolumn{5}{|l|}{ Tolerância } \\
\hline \multicolumn{5}{|l|}{ Ajuda } \\
\hline Objetivos da pesquisa & \multicolumn{2}{|c|}{ Hipóteses da pesquisa } & \multicolumn{2}{|c|}{ Técnicas de análise } \\
\hline $\begin{array}{l}\text { Classificar indivíduos com alta e } \\
\text { baixa pré-disposição à co-criação }\end{array}$ & \multicolumn{2}{|c|}{$\begin{array}{l}\text { Há diferença na pré-disposição à } \\
\text { co-criação entre os indivíduos }\end{array}$} & \multicolumn{2}{|c|}{ Testes de média } \\
\hline $\begin{array}{l}\text { Classificar indivíduos com alta e } \\
\text { baixa preferência por empresas } \\
\text { que praticam o empoderamento }\end{array}$ & \multicolumn{2}{|c|}{$\begin{array}{l}\text { Há diferença na preferência por } \\
\text { empresas que praticam o } \\
\text { empoderamento entre } \\
\text { indivíduos }\end{array}$} & \multicolumn{2}{|c|}{ Testes de média } \\
\hline $\begin{array}{l}\text { Verificar se há diferença na } \\
\text { preferência por empresas que } \\
\text { praticam ou não o } \\
\text { empoderamento dos clientes em } \\
\text { relação à pré-disposição do } \\
\text { indivíduo a co-criar }\end{array}$ & \multicolumn{2}{|c|}{$\begin{array}{l}\text { Indivíduos com alta pré- } \\
\text { disposição à co-criação preferem } \\
\text { empresas que praticam o } \\
\text { empoderamento }\end{array}$} & \multicolumn{2}{|c|}{$\begin{array}{l}\text { Análise descritiva, análise } \\
\text { fatorial e regressão múltipla }\end{array}$} \\
\hline $\begin{array}{l}\text { Classificar grupos de indivíduos } \\
\text { conforme pré-disposição à co- } \\
\text { criação e preferência por } \\
\text { empresa que oferecem ou não o } \\
\text { empoderamento }\end{array}$ & \multicolumn{2}{|c|}{$\begin{array}{l}\text { As diferenças demográficas } \\
\text { permitem a separação em } \\
\text { grupos de acordo com a pré- } \\
\text { disposição dos indivíduos a } \\
\text { praticarem a co-criação e } \\
\text { preferirem empresas que } \\
\text { oferecem ou não o } \\
\text { empoderamento }\end{array}$} & \multicolumn{2}{|c|}{ Regressão logística multinomial } \\
\hline
\end{tabular}

Fonte: Elaborado pelos autores com base em Mazzon (1981).

Quadro 3. Matriz de amarração metodológica

\section{APRESENTAÇÃO DOS RESULTADOS}

Este trabalho contou com 38 respondentes, sendo que a maior parte da amostra é formada por mulheres $(68 \%)$ e apresentam renda familiar superior a $\mathrm{R} \$ 3.000,00$ por mês $(79 \%)$. A Tabela 1 detalha os dados demográficos da amostra.

Foi considerado como "alta pré-disposição à criação" aqueles respondentes cuja média para as respostas às sentenças relativas à co-criação foram superiores a 4, na escala de 1 a 5 . Analogamente, foi considerado como indivíduos com alta preferência por empresas que praticam o empoderamento aquelas respostas com as médias superiores a 4 para as afirmações relativas ao empoderamento. Assim, nesta amostra, 16 respondentes (42\%) foram classificados no grupo daqueles indivíduos com alta pré-disposição à co-criação (o restante no 
grupo com baixa pré-disposição à co-criação) e, ao analisar a preferência por empoderamento, 22 respondentes (58\%) foram classificados no grupo que preferem mais as academias que permitem empoderamento, e 16 (42\%) foram alocados no grupo de indivíduos que não tem tal preferência.

Tabela 1

Descrição dos Respondentes

\begin{tabular}{c|c|l|c}
\hline \multicolumn{1}{c|}{ Gênero } & Porcentagem & \multicolumn{1}{|c}{ Situação na academia } & Porcentagem \\
\hline Feminino & $68 \%$ & $\begin{array}{l}\text { Não está matriculado ou }<3 \\
\text { meses }\end{array}$ & $42 \%$ \\
\hline Masculino & $32 \%$ & Matriculado $>3$ meses & $58 \%$ \\
\hline Renda & Porcentagem & \multicolumn{1}{|c}{ Idade } & Porcentagem \\
\hline Até $\mathrm{R} \$ 3.000,00$ & $21 \%$ & Até 26 anos & $45 \%$ \\
\hline Acima de $\mathrm{R} \$ 3.000,00$ & $79 \%$ & Acima de 26 anos & $55 \%$ \\
\hline
\end{tabular}

Fonte: Elaborada pelos autores a partir das saídas do software SPSS, versão 23.

Após a classificação dos indivíduos nos grupos, foi realizado um teste t para verificar se há diferença estatisticamente significativa entre os grupos. Para a classificação entre alta e baixa pré-disposição à criação, o teste de médias foi significativo ao nível de $5 \%$, o que indica que há diferença nas médias das respostas entre aqueles indivíduos classificados com alta prédisposição à co-criação e aqueles com baixa prédisposição à co-criação, levando à não rejeição de H1. De forma análoga, foi feito o teste de médias para verificar se há diferença estatística entre os indivíduos classificados como tendo preferência por empresas que permitem o empoderamento e aqueles classificados como não tendo esta preferência. 0 teste de médias também foi significativo a 5\%. Assim, a classificação em dois grupos é aceitável, o que leva à não rejeição de $\mathrm{H} 2$.

A partir desta classificação entre os grupos, foi elaborada uma matriz (Tabela 2) relacionando indivíduos entre os grupos, ou seja, classificando-os ao mesmo tempo em relação à sua predisposição à co-criar e a preferir empresas que permitam o empoderamento. Observa-se por meio da Tabela 2 que há indivíduos nos quatro grupos, ou seja, há indivíduos com alta pré-disposição à co-criação que têm alta preferência por empoderamento das empresas, mas também há indivíduos com baixa pré-disposição à cocriação que também têm esta preferência elevada. 0 mesmo ocorre com indivíduos que têm baixa preferência pelo empoderamento.

Tabela 2

Número de Indivíduos Pertencentes a cada Grupo de Análise

\begin{tabular}{|c|c|c|c|}
\hline & & $\begin{array}{l}\text { Pref } \\
\text { emp }\end{array}$ & $\begin{array}{l}\text { pelo } \\
\text { ento }\end{array}$ \\
\hline & & Alta & Baixa \\
\hline \multirow{2}{*}{ Co-criação } & Alta & 11 & 5 \\
\hline & Baixa & 11 & 11 \\
\hline
\end{tabular}

Fonte: Elaborada pelos autores a partir das saídas do software SPSS

Para verificar a validade estatística dos resultados apresentados na Tabela 2, foram criados modelos de regressão para verificar o impacto das variáveis relativas à co-criação (consideradas como variáveis independentes), na preferência pelo empoderamento (utilizado como variável dependente). Foi feita uma análise fatorial com objetivo de reduzir $o$ número de fatores a serem inseridas na equação. Para a criação dos fatores, foram analisados o teste KMO e a significância do teste de esfericidade de Bartlett, que indicam se as variáveis são adequadas ou não para a análise fatorial. Foram considerados os fatores cujo autovalor apresentou resultado superior a 1. Os resultados desses testes, bem como o número de fatores criados para cada variável está apresentado na Tabela 3. Nota-se que para o 
conjunto de variáveis "Tolerância" não foi criado nenhum fator, uma vez que o teste de esfericidade de Bartlett não teve a hipótese nula rejeitada, indicando que as variáveis não eram adequadas para se realizar a análise fatorial.

Tabela 3

Análise Fatorial dos Construtos de Co-criação

\begin{tabular}{l|c|c|c}
\multicolumn{1}{c|}{ Construto } & Teste KMO & $\begin{array}{c}\text { Sig. } \\
\text { Bartlett }\end{array}$ & $\begin{array}{c}\text { No fatores } \\
\text { criados }\end{array}$ \\
\hline Busca de informações & 0,620 & 0,005 & 1 \\
\hline Compartilhamento de informações & 0,538 & 0,000 & 1 \\
\hline Comportamento responsável & 0,761 & 0,000 & 1 \\
\hline Interação pessoal & 0,637 & 0,000 & 2 \\
\hline Feedback & 0,655 & 0,000 & 1 \\
\hline Apoio & 0,705 & 0,000 & 1 \\
\hline Ajuda & 0,580 & 0,001 & 1 \\
\hline Tolerância & 0,589 & 0,135 & 0
\end{tabular}

Fonte: Elaborado pelos autores, a partir das saídas do software SPSS

Como tratamento da variável dependente, que é o interesse por empresas que praticam o empoderamento, também foi realizada uma análise fatorial para cada um dos três construtos que formam a variável, objetivando utilizar os fatores criados como variável dependente em cada uma das especificações do modelo de regressão realizadas. Para este conjunto de construtos, todos os testes de KMO e de esfericidades de Bartlett mostraram resultados adequados para a análise fatorial e foi criado um fator para cada construto, conforme apresentado na Tabela 4. Esses fatores serão utilizados como variáveis dependentes nas regressões.

Tabela 4

Análise Fatorial dos Construtos de Empoderamento

\begin{tabular}{l|c|c|c}
\multicolumn{1}{c|}{ Construto } & Teste KMO & $\begin{array}{c}\text { Sig. } \\
\text { Bartlett }\end{array}$ & $\begin{array}{c}\text { No fatores } \\
\text { criados }\end{array}$ \\
\hline Escolha do serviço & 0,494 & 0,004 & 1 \\
\hline Impacto & 0,659 & 0,000 & 1 \\
\hline Obtenção de informações & 0,668 & 0,000 & 1 \\
\hline
\end{tabular}

Fonte: Elaborado pelos autores, a partir das saídas do software SPSS

A primeira especificação de regressão relacionou a escolha do serviço (Variável Dependnete -VD) com as variáveis independentes relacionadas à pré-disposição à co-criação. A Tabela 5 apresenta os coeficientes da regressão e a significância de cada variável para o modelo. Nota-se que, para a disposição para "Escolha do Serviço", apenas as variáveis busca de informações, ajuda e tolerância foram estatisticamente significativas ao nível de 5\%, sendo que as duas primeiras variáveis se relacionam positivamente e a última tem impacto negativo, o que já é um indício de que não há relação direta entre a pré-disposição em realizar a co-criação e a preferência por empresas que permitem o empoderamento, reforçando os resultados apresentados na Tabela 2. 
Tabela 5

Especificação de Regressão (Variável Dependente: Escolha do Serviço)

\begin{tabular}{|c|c|c|c|c|c|c|}
\hline & \multirow{2}{*}{ Model } & \multicolumn{2}{|c|}{$\begin{array}{c}\text { Unstandardized } \\
\text { Coefficients }\end{array}$} & \multirow{2}{*}{$\begin{array}{c}\begin{array}{c}\text { Standardized } \\
\text { Coefficients }\end{array} \\
\text { Beta }\end{array}$} & \multirow{2}{*}{$\mathrm{t}$} & \multirow{2}{*}{ Sig. } \\
\hline & & B & $\begin{array}{l}\text { Std. } \\
\text { Error }\end{array}$ & & & \\
\hline \multirow[t]{12}{*}{1} & (Constant) & 1,452 & 1,091 & & 1,331 & 0,195 \\
\hline & FAC_Busca_Info & 0,507 & 0,189 & 0,507 & 2,683 & 0,013 \\
\hline & FAC_Comp_Info & 0,284 & 0,212 & 0,284 & 1,339 & 0,192 \\
\hline & FAC_Comp_Resp & $-0,151$ & 0,222 & $-0,151$ & $-0,678$ & 0,504 \\
\hline & FAC_Int_Pess1 & $-0,296$ & 0,208 & $-0,296$ & $-1,425$ & 0,166 \\
\hline & FAC_Int_Pess2 & $-0,146$ & 0,182 & $-0,146$ & $-0,801$ & 0,431 \\
\hline & FAC_Feedback & $-0,005$ & 0,281 & $-0,005$ & $-0,019$ & 0,985 \\
\hline & FAC_Apoio & 0,078 & 0,328 & 0,078 & 0,237 & 0,815 \\
\hline & FAC_Ajuda & 0,562 & 0,194 & 0,562 & 2,893 & 0,008 \\
\hline & Tolerancia1 & $-0,432$ & 0,194 & $-0,499$ & $-2,226$ & 0,035 \\
\hline & Tolerancia2 & 0,014 & 0,146 & 0,016 & 0,097 & 0,924 \\
\hline & Tolerancia3 & $-0,113$ & 0,221 & $-0,093$ & $-0,513$ & 0,612 \\
\hline
\end{tabular}

Fonte: Saída do software SPSS, versão 23, a partir de dados coletados pelos autores.

A segunda especificação de regressão considerou "Impacto" como variável dependente, ou seja, um dos construtos que formam a preferência dos clientes em relação a empresas que permitem o empoderamento. Rodando a regressão com as mesmas variáveis independentes do modelo anterior, tem-se os resultados apresentados na Tabela 6. Nesta especificação, nenhuma das variáveis foi estatisticamente significativa ao nível de 5\%, o que indica que a pré-disposição à co-criação não influencia na preferência por empresas que permitem o empoderamento em relação ao construto "impacto".

Tabela 6

Especificação de Regressão (Variável Dependente: Impacto)

\begin{tabular}{|c|c|c|c|c|c|c|}
\hline & \multirow{2}{*}{ Model } & \multicolumn{2}{|c|}{$\begin{array}{c}\text { Unstandardized } \\
\text { Coefficients }\end{array}$} & \multirow{2}{*}{$\begin{array}{c}\text { Standardized } \\
\text { Coefficients } \\
\text { Beta }\end{array}$} & \multirow{2}{*}{$\mathrm{T}$} & \multirow{2}{*}{ Sig. } \\
\hline & & B & $\begin{array}{l}\text { Std. } \\
\text { Error }\end{array}$ & & & \\
\hline \multirow[t]{12}{*}{1} & (Constant) & 0,366 & 1,169 & & 0,313 & 0,757 \\
\hline & FAC_Busca_Info & 0,406 & 0,202 & 0,406 & 2,005 & 0,056 \\
\hline & FAC_Comp_Info & 0,178 & 0,227 & 0,178 & 0,783 & 0,440 \\
\hline & FAC_Comp_Resp & 0,068 & 0,238 & 0,068 & 0,287 & 0,777 \\
\hline & FAC_Int_Pess1 & $-0,081$ & 0,223 & $-0,081$ & $-0,363$ & 0,720 \\
\hline & FAC_Int_Pess2 & 0,134 & 0,195 & 0,134 & 0,687 & 0,498 \\
\hline & FAC_Feedback & 0,078 & 0,302 & 0,078 & 0,258 & 0,798 \\
\hline & FAC_Apoio & $-0,149$ & 0,351 & $-0,149$ & $-0,425$ & 0,675 \\
\hline & FAC_Ajuda & 0,380 & 0,208 & 0,380 & 1,823 & 0,080 \\
\hline & Tolerancia1 & $-0,131$ & 0,208 & $-0,152$ & $-0,631$ & 0,533 \\
\hline & Tolerancia2 & 0,031 & 0,157 & 0,034 & 0,197 & 0,845 \\
\hline & Tolerancia3 & $-0,034$ & 0,237 & $-0,028$ & $-0,143$ & 0,887 \\
\hline
\end{tabular}

Fonte: Saída do software SPSS, versão 23, a partir de dados coletados pelos autores.

Finalmente, a terceira especificação de regressão foi rodada considerando a "obtenção de informações" como variável dependente. Os resultados da regressão estão apresentados na Tabela 7. Nesta especificação apenas as variáveis relacionadas à busca de informações e à ajuda foram estatisticamente significativas ao nível de 5\% para explicar a preferência por empresas que permitem o empoderamento dos clientes. 
Tabela 7

Especificação de Regressão (Variável Dependente: Obtenção de Informações)

\begin{tabular}{|c|c|c|c|c|c|c|}
\hline & \multirow{2}{*}{ Model } & \multicolumn{2}{|c|}{$\begin{array}{c}\text { Unstandardized } \\
\text { Coefficients }\end{array}$} & \multirow{2}{*}{$\begin{array}{c}\text { Standardized } \\
\text { Coefficients } \\
\text { Beta }\end{array}$} & \multirow{2}{*}{$\mathrm{T}$} & \multirow{2}{*}{ Sig. } \\
\hline & & $\mathrm{B}$ & $\begin{array}{l}\text { Std. } \\
\text { Error }\end{array}$ & & & \\
\hline \multirow[t]{12}{*}{1} & (Constant) & 1,645 & 0,964 & & 1,707 & 0,100 \\
\hline & FAC_Busca_Info & 0,410 & 0,167 & 0,410 & 2,460 & 0,021 \\
\hline & FAC_Comp_Info & 0,088 & 0,187 & 0,088 & 0,469 & 0,643 \\
\hline & FAC_Comp_Resp & $-0,111$ & 0,196 & $-0,111$ & $-0,565$ & 0,577 \\
\hline & FAC_Int_Pess1 & $-0,092$ & 0,184 & $-0,092$ & $-0,503$ & 0,619 \\
\hline & FAC_Int_Pess2 & $-0,110$ & 0,161 & $-0,110$ & $-0,686$ & 0,499 \\
\hline & FAC_Feedback & $-0,145$ & 0,249 & $-0,145$ & $-0,585$ & 0,564 \\
\hline & FAC_Apoio & 0,292 & 0,289 & 0,292 & 1,009 & 0,322 \\
\hline & FAC_Ajuda & 0,582 & 0,172 & 0,582 & 3,392 & 0,002 \\
\hline & Tolerancia1 & $-0,141$ & 0,172 & $-0,163$ & $-0,822$ & 0,419 \\
\hline & Tolerancia2 & $-0,129$ & 0,129 & $-0,142$ & $-0,998$ & 0,327 \\
\hline & Tolerancia3 & $-0,242$ & 0,195 & $-0,198$ & $-1,239$ & 0,226 \\
\hline
\end{tabular}

Fonte: Saída do software SPSS, versão 23, a partir de dados coletados pelos autores.

Os resultados obtidos a partir das três regressões multinomiais previamente descritas permitem a rejeição de H3 (indivíduos com alta pré-disposição à co-criação preferem empresas que praticam o empoderamento), visto que apenas duas entre sete variáveis relacionadas à pré-disposição para a co-criação se mostraram estatisticamente significativas. Outro fator de rejeição da hipótese é por meio da observação da Tabela 2, que mostra uma divisão relativamente homogênea dos respondentes nos grupos criados.

Para a identificação de quais indivíduos, segundo as variáveis demográficas, pertencem aos grupos descritos na Tabela 2 foi rodada uma regressão logística multinomial em que a variável dependente eram os números dos grupos, os fatores foram a renda, gênero e tempo que o indivíduo está matriculado na academia e a idade foi utilizada como covariável, por ser uma variável métrica. Ao se analisar o teste de significância dos coeficientes do modelo final por meio do teste $F$ nota-se que seu p-valor foi 0,469 , ou seja, não se rejeita a hipótese nula de que não há coeficientes estatisticamente significativos ao nível de 5\%. Desta forma, conclui-se diante do modelo que as variáveis demográficas utilizadas na regressão não são capazes de explicar a classificação dos indivíduos na Tabela 2, rejeitando a hipótese $\mathrm{H} 4$ de que as diferenças demográficas permitem a separação em grupos de acordo com a prédisposição dos indivíduos a praticarem a co- criação e preferirem empresas que oferecem ou não o empoderamento.

\section{DISCUSSÃO}

Verificou-se na presente pesquisa que há diferença entre grupos de indivíduos que têm pré-disposição para co-criar e os que não têm, e entre grupos de indivíduos que têm preferência por empresas que promovem o empoderamento e as que não promovem. Todavia, não foi encontrada relação na interação entre esses quatro grupos de clientes, ou seja, não é possível afirmar, por exemplo, que aquele indivíduo que possui o comportamento de co-criação é o mesmo que prefere empresas que empoderam seus clientes.

Desta forma, as empresas que empoderam seus clientes devem efetuar essa ação como estratégia, e aplica-la de formas variadas, conforme relatado por Acar e Puntoni (2016). Os autores sugerem que, para tirar vantagem do empoderamento, as organizações precisam oferecer formas profundas e brandas de empoderamento ao mesmo tempo e adaptá-las conforme o tipo de cliente. Uma suposição para, a não preferência por empresas que empoderam pode ser a indisposição de clientes gastarem seus recursos, como tempo ou mesmo esforço cognitivo para criar os serviços em conjunto com as empresas, preferindo ser agentes passivos da relação (Acar \& Puntoni, 2016). Como visto na Tabela 2 em que é demonstrada uma divisão praticamente 
homogênea dos indivíduos, não há relação entre a pré-disposição em co-criar e preferência por empresas que empoderam os clientes.

Os resultados também mostraram que não foi possível classificar os indivíduos nos grupos segundo suas variáveis demográficas, o que indica que a renda, gênero, idade ou tempo que o indivíduo está matriculado em uma academia não são capazes de explicar a preferência pela co-criação e preferência por empresas que permitem o empoderamento. Outras variáveis podem ser analisadas para explicar a preferência pela co-criação e preferência por empresas que permitem o empoderamento variáveis comportamentais, por exemplo.

\section{CONCLUSÃO}

0 objetivo deste artigo é verificar se há diferença na preferência dos clientes (tenham eles maior ou menor tendência a ter comportamento de co-criação), em relação aos tipos de empresas (considerando as que os empoderam ou não). Para alcançar o objetivo foi realizada uma análise de regressão logística multinomial a partir de dados coletados por meio de questionário. Os resultados da regressão não se mostraram significativos, o que permite supor que não há diferença na preferência dos consumidores e seu comportamento de co-criação segundo as variáveis demográficas utilizadas. Os resultados da pesquisa trouxeram implicações gerenciais, demonstrando que existem diversos tipos de cliente e não é porque o cliente gosta de co-criar que ele, necessariamente, prefira empresas que o empoderam. A co-criação pode exigir recursos, e mesmo clientes engajados no processo podem não ter as competências necessárias para participarem desse processo.

Como limitação encontrada no desenvolvimento do trabalho foi detectada a utilização de apenas variáveis demográficas: renda, idade, e gênero para fazer a divisão entre os grupos, sendo assim, a utilização de variáveis comportamentais pode ser inserida em pesquisas futuras. Outra limitação encontrada na pesquisa foi a análise apenas em um ambiente de serviço (as academias de ginásticas), não analisando o ambiente de bens. Assim, como agenda de pesquisa, sugere-se a inclusão de variáveis comportamentais no estudo, bem como abranger outros tipos de atividade dentro do setor de serviço ou mesmo no setor de bens.

\section{REFERÊNCIAS}

Acar, 0. A. \& Puntoni, S. (2016). Customer empowerment in the digital age. Journal of Advertising Research, 56(1), 4-8.

Dijk, J., Antonides, G. \& Schillewaert, N. (2014). Effects of co-creation claim on consumer brand perceptions and behavioural intentions. International Journal of Consumer Studies, 38(1), 110-118.

Fuchs, C. \& Schreier, M. (2011). Customer empowerment in new product development. Journal of Product Innovation Management, 28(1), 17-32.

Grönroos, C. (2000). Creating a relationship dialogue: communication, interaction and value. The marketing review, 1(1), 5-14.

Hilton, T., Hughes, T. \& Chalcraft, D. (2012). Service co-creation and value realisation. Journal of Marketing Management, 28(13-14), 15041519.

Kukk, J., Leppiman, A. \& Pohjola, A. (2015). Designing a business service experience: Customer's perspective on value co-creation. Research in Economics and Business: Central and Eastern Europe, 6(1).

Minkiewicz, J., Evans, J. \& Bridson, K. (2014). How do consumers co-create their experiences? An exploration in the heritage sector. Journal of Marketing Management, 30(1-2), 30-59.

Pranic, L. \& Roehl, W. S. (2012). Rethinking service recovery: a customer empowerment (CE) perspective. Journal of Business Economics \& Management, 13(2), 242-260.

Prentice, C., Han, X.-Y. \& Li, Y.-Q. (2016). Customer empowerment to co-create service designs and delivery: Scale development and validation. Services Marketing Quarterly, 37(1), 36-51.

Shamim, A. \& Ghazali, Z. (2014). A conceptual model for developing customer value co-creation behaviour in retailing. Global Business and Management Research, 6(3), 185.

Telles, R. (2001). A efetividade da "matriz de amarração" de Mazzon nas pesquisas em Administração. Revista de Administração, 36(4), 64-72.

Terblanche, N. S. (2014). Some theoretical perspectives of co-creation and co-production of value by customers. Acta Commercii, 14(2), 8 pages.

Tiu Wright, L., Pires, G. D., Stanton, J. \& Rita, P. (2006). The internet, consumer 
empowerment and marketing strategies. European Journal of Marketing, 40(9/10), 936949.

Vargo, S. L. \& Lusch, R. F. (2004). Evolving to a new dominant logic for marketing. Journal of Marketing, 68(1), 1-17.

Vernette, E. \& Hamdi-Kidar, L. (2013). Co-creation with consumers: who has the competence and wants to cooperate? International Journal of Market Research, 55(4), 2-20.

Yi, Y. \& Gong, T. (2013). Customer value co-creation behavior: Scale development and validation. Journal of Business Research, 66(9), 12791284.

\title{
If you like to co-create, do you like to be empowered? Co-creation of clients and their preferences for empowerment
}

\begin{abstract}
This paper aimed to verify if there are any differences between groups of consumers (considering their preferences towards co-creation) regarding which companies they prefer (those who empower their clients versus those that do not). In order to achieve this goal, a survey was conducted to measure clients' cocreation behavior and their preferences for businesses that empower their clients. The research was conducted with gyms' consumers, because this type of business allows cocreation and consumer empowerment. Data was analyzed through factorial analysis, $t$ tests and logistic regression. Results evidence that consumers' cocreation behavior does not affect their preferences by type of business.
\end{abstract}

Keywords: Co-creation, Consumer empowerment, Service sector. 